\title{
Blue rubber bleb nevus syndrome: an unusual cause of intestinal bleeding in the elderly
}

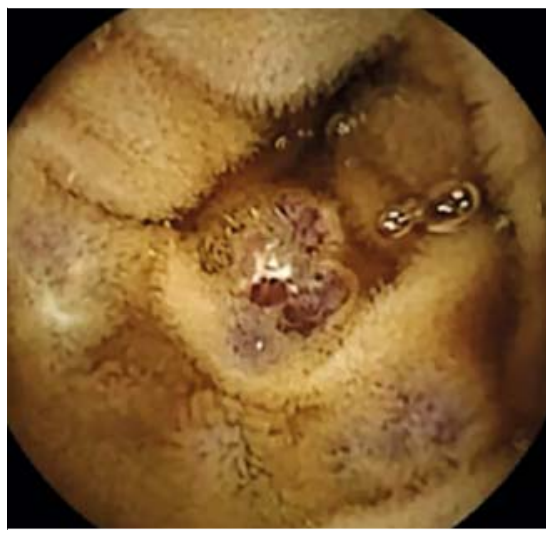

- Fig. 1 Capsule endoscopy shows many blue angiodysplasias along the jejunum.

Blue rubber bleb nevus syndrome (or Bean syndrome) is a rare cause of gastrointestinal bleeding. Only three cases have been reported in the elderly [1-3].

A 70-year-old man was hospitalized for recurrent and severe digestive bleeding for one month. He had recently undergone coronary stent surgery requiring antiplatelet and anticoagulant treatments, leading to lower gastrointestinal (GI) bleeding and severe anemia. Daily blood transfusions were required. Oesogastro-duodenal endoscopy and colonoscopy were normal. A small bowel capsule endoscopy showed many ectasia of the vessels along the small bowel with active and diffuse bleeding, suggesting blue rubber bleb nevus syndrome ( $\triangleright$ Fig. $\mathbf{1}$, - Video 1). Abdominal computed tomography (CT) scan and multiphase CT enterography showed arteriovenous malformations in the jejunum and ileum without active bleeding. However, they were too numerous to be treated by endoscopic coagulation. Radiological embolization was not possible because of the serious risk of mesenteric ischemia.

We decided to perform an exploratory laparotomy in conjunction with an intraoperative endoscopy of the small bowel. We observed many transparietal angiodysplasias along 3 meters of the small

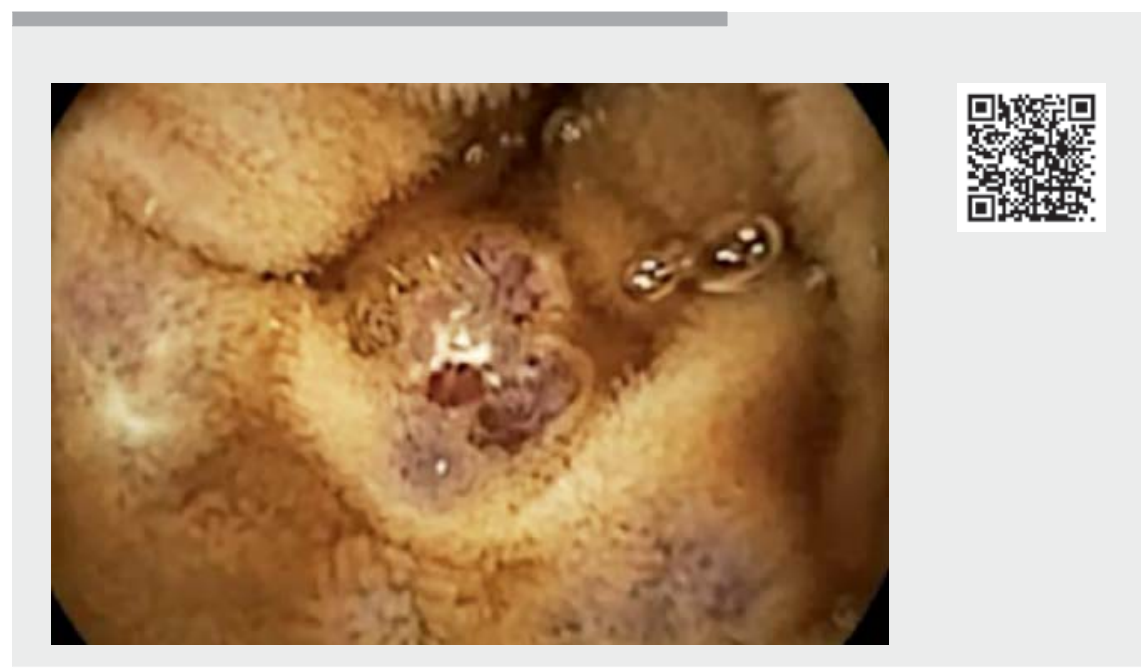

$\checkmark$ Video 1 Diagnosis and management of a small-bowel blue rubber bleb nevus syndrome.

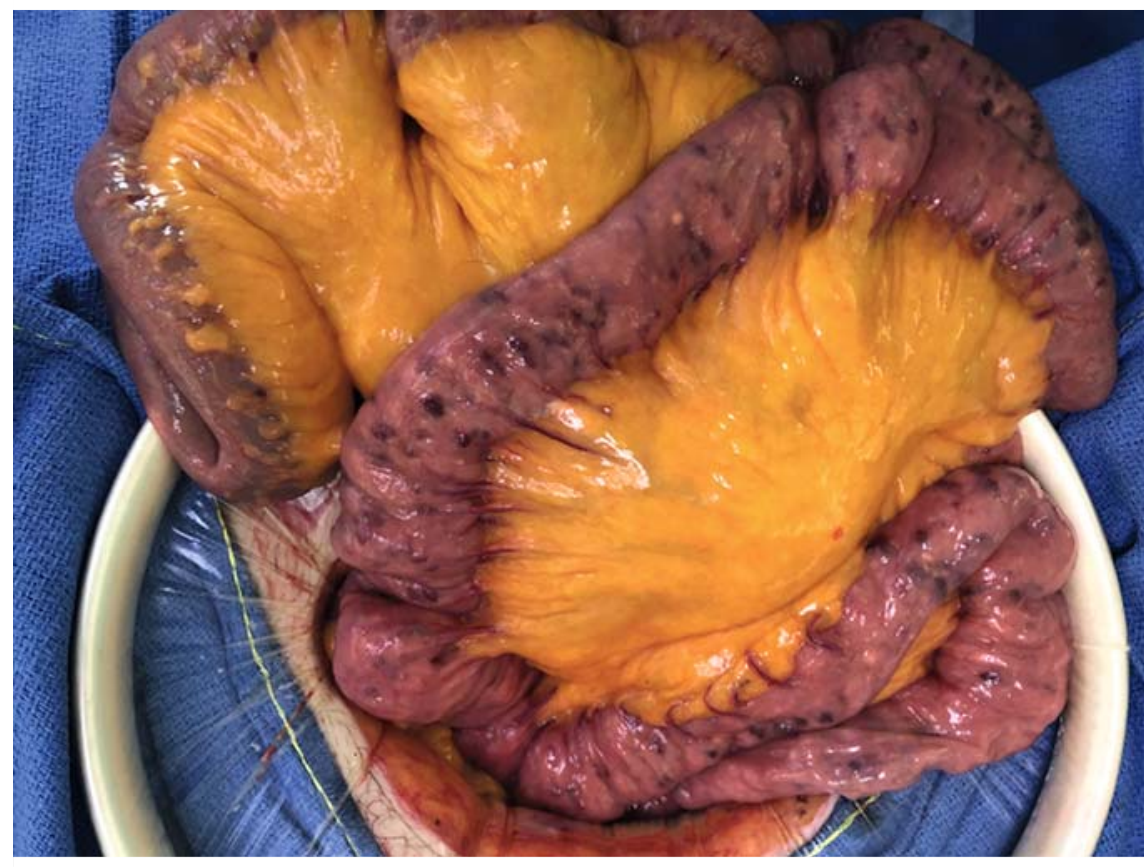

- Fig. 2 Exploratory laparotomy shows many transparietal angiodysplasias along the small bowel. Most of them are blue, but some are yellowish.

bowel starting at the angle of Treitz ( Fig. 2). The ileum seemed to be free of these lesions. The intraoperative enteroscopy confirmed that there were no le- sions in the ileum and 100 arteriovenous malformations in the jejunum with some active bleeding. We decided to perform an extensive bowel resection, removing 

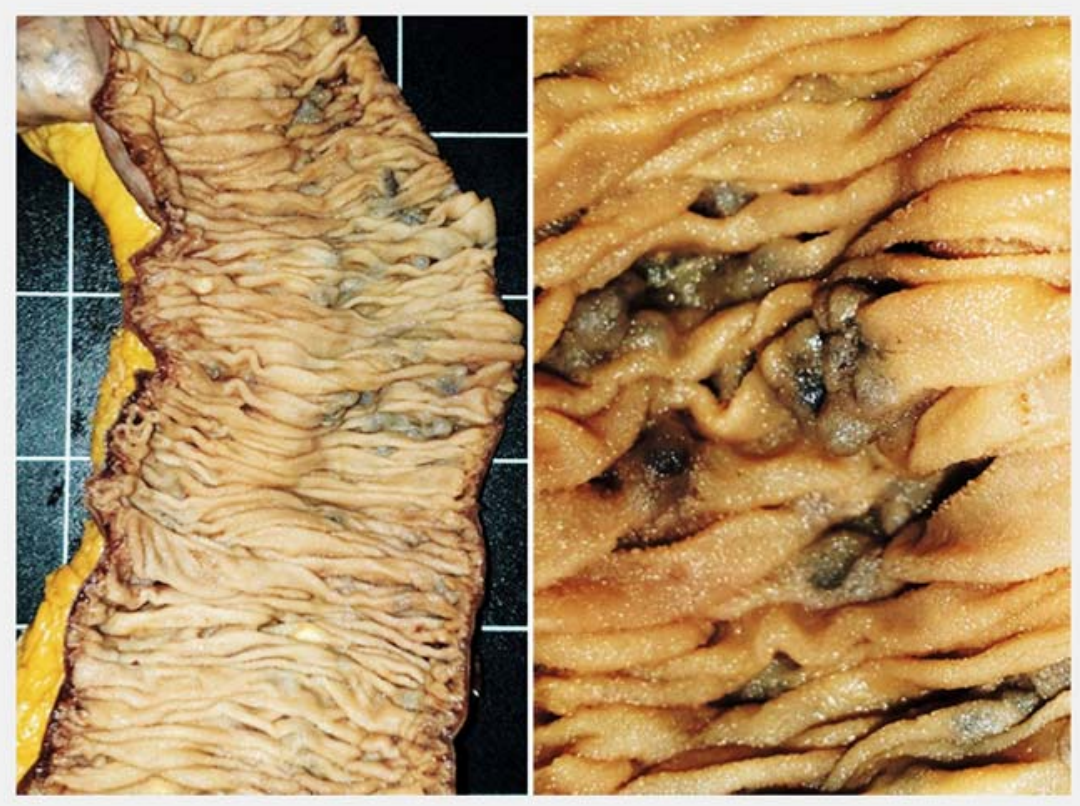

- Fig. 3 Macroscopic view shows flat and polypoid submucosal lesions. Most of them are blue, but some are yellowish.

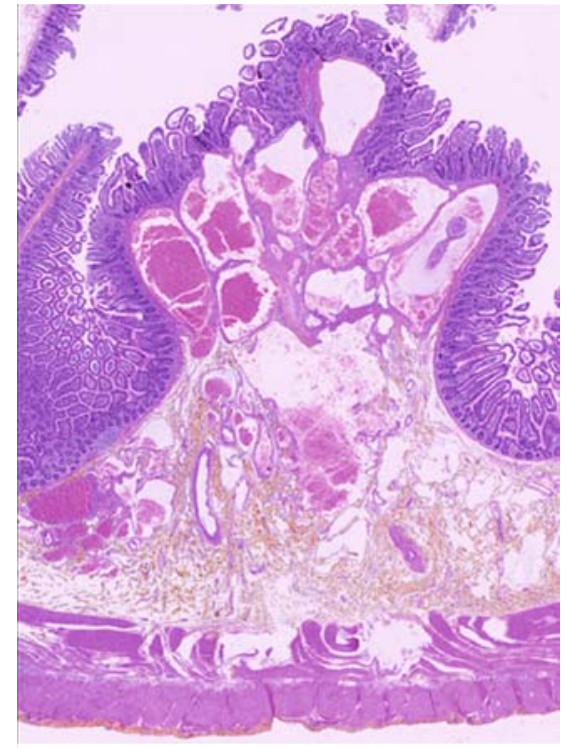

- Fig. 4 Microscopic analysis of benign angiodysplasias with hemangiomatous and lymphangiomatous components.

\section{References}

[1] Aron J et al. An unusual cause of gastrointestinal bleeding in a haemodialysis patient. Hemodial Int 2018; 22: E60-E62

[2] Gião AntunesAS et al. Blue rubber bleb nevus syndrome: a delayed diagnosis. GE Port J Gastroenterol 2017; 24: 101-103

[3] Baker AL et al. Gastrointestinal bleeding due to blue rubber bleb nevus syndrome. A case diagnosed by angiography. Gastroenterology $1971 ; 61: 530-534$

\section{Bibliography}

Endoscopy 2022; 54: E53-E54

DOI $10.1055 / \mathrm{a}-1381-6267$

ISSN 0013-726X

published online 5.3.2021

(c) 2021. Thieme. All rights reserved.

Georg Thieme Verlag KG, Rüdigerstraße 14,

70469 Stuttgart, Germany

\section{Competing interests}

The authors declare that they have no conflict of interest.

\section{Diane Mege, MD, PhD}

Aix Marseille Université, APHM, Department of Digestive Surgery, Timone University Hospital, 264 Rue Saint-Pierre, 13005 Marseille, France

Fax: +33-4-91-385355

dr.dianemege@gmail.com 